\title{
To Cut Is to Cure: Can We Really Apply Z11 in Practice?
}

\author{
Monica Morrow, $\mathrm{MD}^{1}$ and Armando E. Giuliano, $\mathrm{MD}^{2}$ \\ ${ }^{1}$ Breast Service, Department of Surgery, Memorial Sloan-Kettering Cancer Center, New York, NY; ${ }^{2}$ Cedars Sinai Medical \\ Center, Los Angeles, CA
}

Axillary dissection has been a standard part of the local therapy of breast cancer since the popularization of the radical mastectomy by William Halstead in 1894. In 1985, 10-year outcomes from the National Surgical Adjuvant Breast and Bowel Project (NSABP) B04 study were published and showed that in clinically node-negative women, there was no survival advantage for immediate axillary dissection compared to observation and delayed dissection if clinical nodal disease developed. ${ }^{1}$ In addition, only about half of the patients with nodal metastases (based on the incidence of metastases in the dissection arm) went on to develop clinically evident nodal recurrence. Although this study was extremely influential in our thinking about breast cancer biology, it did not lead to the abandonment of axillary dissection, primarily because nodal status was a selection factor for the use of adjuvant systemic therapy at that time.

Fast forward to the present. Sentinel node biopsy allows us to reliably stage patients as node positive or node negative. Multiple tumor characteristics, many of them molecular, are now used to determine prognosis, and adjuvant systemic therapy is widely used in both node positive and node negative breast cancer patients. ${ }^{2,3}$ In this setting, the American College of Surgeons (ACOSOG) Z11 trial was designed to address the question of whether axillary dissection is necessary for survival or local control in the context of breast-conserving surgery with whole breast irradiation and systemic therapy. The answer from the study was a clear no. At a median follow-up of 6.3 years, the rate of nodal recurrence in the sentinel nodeonly arm was $0.9 \%$ compared to $0.4 \%$ in the dissection

(C) Society of Surgical Oncology 2011

First Received: 14 April 2011;

Published Online: 30 June 2011

M. Morrow, MD

e-mail: morrowm@mskcc.org arm, and there was no trend toward an improvement in disease-free or overall survival with axillary dissection. ${ }^{4,5}$ Although the finding of better outcomes with the addition of treatment is always hailed as an "advance," the ability to decrease treatment without changing outcome is often a cause for concern, and many questions are now being raised about whether we should really believe the results of Z11 and change practice.

First and foremost among these issues is the closure of the study before recruitment of the planned sample size. In part, this occurred because the event rate was much lower than anticipated at the time of study design thanks to both improvements in therapy and increased uptake of screening mammography - a happy event for women with breast cancer if not for statistical purists. In addition, recruitment to the study was slow, apparently because many surgeons already knew the answer to the study question. It is worth noting that study sample sizes are estimates of the number of patients needed to reliably exclude a statistically significant difference in outcomes before the actual rate of events in each group is known. In spite of failing to achieve the planned sample size, the predefined statistical analysis plan of Z11 was able to demonstrate the noninferiority of sentinel node biopsy alone for overall survival with a $P$ value of 0.008 . The $95 \%$ confidence intervals of the hazard ratio for survival do not cross 1.3 , the predefined point at which the treatments would not be considered equal, indicating that the results would not be expected to change with a larger sample size. Total locoregional recurrences, disease-free survival, and overall survival all numerically favor the sentinel node group, suggesting that the observed results do not reflect a statistical power problem.

Other concerns about the Z11 study are related to the length of follow-up and its applicability to subgroups of estrogen receptor (ER)-negative women and young women. The issue of length of follow-up is readily addressed on the basis of other published studies of 
variations in axillary treatment. In NSABP B04, the median time to axillary recurrence was 14.8 months in clinically node-negative women not undergoing axillary dissection. ${ }^{1}$ In populations of largely ER-positive patients comparable to those in $\mathrm{Z} 11$, such as those reported by Martelli et al. and Greco et al., ${ }^{6,7}$ the median times to axillary recurrence were 33.0 and 30.6 months, respectively. Even in a group of 568 node positive, ER-positive patients treated with breast conservation, axillary dissection, and in some cases nodal irradiation, the incidence of nodal recurrence between 5 and 10 years of follow-up increased by only $1 \%$, from 1 to $2 \% .^{8}$ The aggregate data strongly indicate that the follow-up period of 6.3 years is sufficient to capture the majority of axillary recurrences.

Should the results of Z11 be applied to ER-negative women or young women? After all, only $16 \%$ of the patients in each arm of the study were hormone receptor negative. The key to answering this question is whether or not age or ER status are predictors of an increased risk of nodal recurrence. An exploratory analysis in Z11 demonstrated no trend toward increased locoregional recurrence on the basis of hormone receptor negativity. Targeted therapy is a powerful method for reducing locoregional recurrence, and the addition of trastuzumab to chemotherapy was shown in randomized trials to reduce the risk of locoregional recurrence by $50 \%$, leaving the subgroup of women with triple-negative breast cancer (ER, progesterone receptor, HER2 negative) for whom no targeted therapy is available as the group that is potentially of greatest concern in applying the Z11 results. ${ }^{9}$ However, both Crabb et al. and Wiechmann et al. ${ }^{10,11}$ have shown that triple-negative breast cancers are less likely than those expressing ER or HER2 to metastasize to axillary nodes after adjustment for size and grade, and Wiechmann et al. also demonstrated that this subgroup was less likely to have involvement of 4 or more nodes. This information provides some reassurance that although prognosis in triple-negative breast cancer is poor, this is not due to a heavy burden of nodal disease in a high proportion of patients. Further reassurance is provided by Grills et al. ${ }^{8}$ in a study of 1,500 patients treated with breast-conserving surgery, axillary dissection, and breast irradiation in which receptor status was not a predictor of nodal relapse in multivariate analysis.

That leaves young women as a cause for concern. In the report of the locoregional outcomes of Z11, young age was a predictor of locoregional recurrence in multivariate analysis. ${ }^{5}$ This was due to an increased rate of ipsilateral breast tumor recurrence in younger women. In the sentinel node-only arm of the study there were 5 recurrences in women under age 50: 4 in-breast recurrences and 1 nodal. In the axillary dissection arm there were 11 recurrences in women under age 50: 9 in the breast and 2 nodal. The relationship between young age and an increased rate of inbreast recurrence is well documented in clinical trials, but we are unable to find documentation that isolated nodal recurrence, a rare event, is more common in the young. ${ }^{12,13}$ In one study of 1500 patients, including 467 under age 50, age less than 45 years was not a predictor of nodal recurrence. $^{8}$

In the end, what are we left with? Although it certainly would have been nice to have more patients in the Z11 study overall, more ER-negative patients, and more young women, the study composition reflects the fact that breast cancer most commonly occurs in older women and is usually hormone receptor positive. We have only ourselves to blame for the number and type of patients recruited to this study. There is no follow-up or confirmatory study coming down the road, and the time to launch such a study in women undergoing breast conservation has passed. The use of axillary dissection for patients with positive sentinel nodes was decreasing before the publication of ${\mathrm{Z} 11 .{ }^{14}}^{14}$ Surgeons must ask themselves whether they are more comfortable using their own clinical impressions and retrospectively derived nomograms to make the decision about performing an axillary dissection for a positive sentinel node than they are with the use of criteria employed in a prospective, randomized trial. Meanwhile, there is ample opportunity for critics to rectify the limitations of Z11 in the next generation of trials, which should address the role of axillary dissection in patients excluded from Z11-those undergoing mastectomy, those who have received neoadjuvant therapy, and those having breast conservation without whole breast radiotherapy.

\section{DISCLOSURES None}

\section{REFERENCES}

1. Fisher B, Redmond C, Fisher ER, Bauer M, Wolmark N, Wickerham DL, et al. Ten-year results of a randomized clinical trial comparing radical mastectomy and total mastectomy with or without radiation. $N$ Engl J Med. 1985;312:674-81.

2. Sorlie T, Perou CM, Tibshirani R, Aas T, Geisler S, Johnsen H, et al. Gene expression patterns of breast carcinomas distinguish tumor subclasses with clinical implications. Proc Natl Acad Sci USA. 2001;98:10869-74.

3. van de Vijver MJ, He YD, van't Veer LJ, Dai H, Hart AA, Voskuil DW, et al. A gene-expression signature as a predictor of survival in breast cancer. N Engl J Med. 2002;347:1999-2009.

4. Giuliano AE, Hunt KK, Ballman KV, Beitsch PD, Whitworth PW, Blumencranz PW, et al. Axillary dissection vs no axillary dissection in women with invasive breast cancer and sentinel node metastasis: a randomized clinical trial. JAMA. 2011;305:569-75.

5. Giuliano AE, McCall L, Beitsch P, Whitworth PW, Blumencranz $\mathrm{P}$, Leitch AM, et al. Locoregional recurrence after sentinel lymph node dissection with or without axillary dissection in patients with sentinel lymph node metastases: the American College of Surgeons Oncology Group Z0011 randomized trial. Ann Surg. 2010;252:426-32. 
6. Martelli G, Miceli R, Daidone MG, Vetrella G, Cerrotta AM, Piromalli D, et al. Axillary dissection versus no axillary dissection in elderly patients with breast cancer and no palpable axillary nodes: results after 15 years of follow-up. Ann Surg Oncol. 2011;18:125-33.

7. Greco M, Agresti R, Cascinelli N, Casalini P, Giovanazzi R, Maucione A, et al. Breast cancer patients treated without axillary surgery: clinical implications and biologic analysis. Ann Surg. 2000;232:1-7.

8. Grills IS, Kestin LL, Goldstein N, Mitchell C, Martinez A, Ingold $\mathrm{J}$, et al. Risk factors for regional nodal failure after breast-conserving therapy: regional nodal irradiation reduces rate of axillary failure in patients with four or more positive lymph nodes. Int $J$ Radiat Oncol Biol Phys. 2003;56:658-70.

9. Romond EH, Perez EA, Bryant J, Suman VJ, Geyer CE Jr, Davidson NE, et al. Trastuzumab plus adjuvant chemotherapy for operable HER2-positive breast cancer. N Engl J Med. 2005;353: 1673-84.

10. Crabb SJ, Cheang MC, Leung S, Immonen T, Nielsen TO, Huntsman DD, et al. Basal breast cancer molecular subtype predicts for lower incidence of axillary lymph node metastases in primary breast cancer. Clin Breast Cancer. 2008;8:249-56.

11. Wiechmann L, Sampson M, Stempel M, Jacks LM, Patil SM, King T, et al. Presenting features of breast cancer differ by molecular subtype. Ann Surg Oncol. 2009;16:2705-10.

12. Anderson SJ, Wapnir I, Dignam JJ, Fisher B, Mamounas EP, Jeong $\mathrm{JH}$, et al. Prognosis after ipsilateral breast tumor recurrence and locoregional recurrences in patients treated by breast-conserving therapy in five National Surgical Adjuvant Breast and Bowel Project protocols of node-negative breast cancer. J Clin Oncol. 2009;27:2466-73.

13. Bartelink H, Horiot JC, Poortmans PM, Struikmans H, Van den Bogaert W, Fourquet A, et al. Impact of a higher radiation dose on local control and survival in breast-conserving therapy of early breast cancer: 10-year results of the randomized boost versus no boost EORTC 22881-10882 trial. J Clin Oncol. 2007;25:3259-65.

14. Bilimoria KY, Bentrem DJ, Hansen NM, Bethke KP, Rademaker AW, Ko CY, et al. Comparison of sentinel lymph node biopsy alone and completion axillary lymph node dissection for nodepositive breast cancer. J Clin Oncol. 2009;27:2946-53. 